\title{
Pengaruh Budaya Kerja dan Organizational Citizenship Behavior Terhadap Kinerja Karyawan PT. Kaltrabu Indah Tour dan Travel Banjarmasin
}

\author{
Fanlia Adiprimadana Sanjaya \\ Universitas Islam Kalimantan Muhammad Arsyad Al-Banjari \\ Email : fanliadana@gmail.com
}

\begin{abstract}
This research aims to study, analyze, and determine the effect of Work Cultur and, Organizational Citizenship Behavior on Employee Performance PT Kaltrabu Indah Tour \& Travel Banjarmasin. Method of data collection is done by passing the question form on the overall Employee population PT Kaltrabu Indah tours \& Travel Banjarmasin totalling 35 people who then established as the sample of respondents with saturated samples or samples (total as many as 35 people) census respondents. Using quantitative and qualitative analysis also linear regression program simple and multiple linear regression as well as using software MS Excell and SPSS Version 20.0.

The results were obtained as follows: Partially work culture influence the Employee Performance PT. Kaltrabu Indah Tour \& Travel Banjarmasin significant effect. And Partially Organizational Citizenship Behavior influence the Employee Performance PT. Kaltrabu Indah Tour \& Travel Banjarmasin significant effect. Simultaneously influence Work Culture and Organizational Citizenship Behavior Employee Performance PT. Kaltrabu Indah Tour \& Travel Banjarmasin significant effect.
\end{abstract}

Keywords : Work Culture; Organizational Citizenship Behavior; Employee Performance.

Abstrak

Penelitian Tesis ini bertujuan mengkaji, menganalisis, dan mengetahui Pengaruh Budaya Kerja dan Organizational Citizenship Behavior Terhadap Kinerja Karyawan PT Kaltrabu Indah Tour \& Travel Banjarmasin. Metode pengumpulan data dilakukan dengan mengedarkan angket pada keseluruhan populasi Karyawan PT Kaltrabu Indah Tour \& Travel Banjarmasin yang berjumlah 35 orang yang selanjutnya ditetapkan sebagai sampel responden dengan sampel jenuh atau sampel total (sensus) sebanyak 35 orang responden. Dengan menggunakan analisis kuantitatif dan kualitatif juga program regresi linear sederhana dan regresi linear berganda serta menggunakan software MS Excell dan SPSS Versi 20.0.

Hasil penelitian diperoleh sebagai berikut : Secara parsial pengaruh Budaya Kerja terhadap Kinerja Karyawan PT. Kaltrabu Indah Tour \& Travel Banjarmasin berpengaruh signifikan. Dan Secara parsial pengaruh Organizational Citizenship Behavior terhadap Kinerja Karyawan PT. Kaltrabu Indah Tour \& Travel Banjarmasin berpengaruh signifikan. Selanjutnya Secara simultan pengaruh Budaya Kerja dan Organizational Citizenship Behavior, terhadap Kinerja Karyawan PT. Kaltrabu Indah Tour \& Travel Banjarmasin berpengaruh signifikan.

Kata Kunci : Budaya Kerja; Organizational citizenship Behavior; Kinerja Karyawan.

(C) 2020 Jurnal Riset Inspirasi Manajemen dan Kewirausahaan

\section{PENDAHULUAN}

Usaha Travel di masa kini memiliki berbagai peluang dan tantangan di era disrupsi. Hal ini untuk mengantasipasi perkembangan dunia usaha khususnya sektor Tour and Travel selama 15 - 30 tahun ke depan. Usaha atau Bisnis di sektor ini harus mampu mengatasi tantangan dan meraih peluang yang timbul sebagai akibat berbagai perkembangan di dunia usaha khususnya di sektor Tour and Travel. Peluang dan tantangan ini dijabarkan oleh Mayling Oey-Gardiner dan Teguh Dartanto (2018) dalam Seminar Era Disrupsi : Peluang \& Tantangan Bisnis di Indonesia.

Untuk meraih peluang dan tantangan tersebut penulis merasakan bahwa faktor yang cukup relevan saat ini antara lain budaya kerja dan organizational citizenship behavior karyawan guna meraih kinerja karyawan yang optimal dan dapat meraih peluang serta mengatasi tantangan di era disrupsi ini.

Secara umum diketahui bahwa kinerja karyawan merupakan faktor utama untuk mencapai 
keberhasilan karyawan di suatu unit bisnis (perusahaan). Permasalahan kinerja karyawan dapat dilihat dari masih adanya karyawan yang keluar kantor di waktu jam kerja dengan kepentingan pribadi. Kurangnya partisipasi senior terhadap karyawan baru dalam menumpuknya tugas, dikarenakan tugas yang harus dikerjakan tidak untuk senior sehingga terjadinya penundaan pekerjaan yang seharusnya diselesaikan tepat pada hari itu juga.

\section{KAJIAN LITERATUR}

Budaya kerja merupakan suatu pemahaman, sikap dan perilaku yang diterapkan orang-orang sewaktu melaksanakan pekerjaan dalam suatu karyawan/ institusi. Faris (2014) mengemukakan bahwa mutu sumberdaya manusia Indonesia yang tidak mampu bersaing, hal ini disebabkan oleh karena faktor budaya kerja yang juga masih lemah dan tidak merata. Apabila alat ukur yang tepat dalam mengkategori budaya kerja yang berkualitas belum ditentukan, maka akan terlihat sebagian pimpinan dalam berbagai perusahaan memberi tugas kepada karyawan di lingkungan perusahaannya tanpa melihat kemampuan yang dimiliki.

Faktor lainnya yang mendukung tercapainya kinerja yang tinggi diantaranya tingkat Organizatinal Citizenship Behavior (OCB) yang dimiliki di suatu karyawan bersangkutan. Robin dan Judge (2008) menyatakan bahwa karyawan yang memiliki OCB yang baik akan memiliki kinerja yang baik pula. OCB menurut Turnley dan Bloodgood (2012) adalah perilaku karyawan yang bersedia bekerja melebihi peran atau tugas yang diwajibkan dan tidak secara langsung diakui oleh system reward. Karyawan akan dapat menghasilkan kinerja dengan baik bilamana terdapat suatu kelaziman di mana karyawan tidak hanya melakukan tugas pokoknya saja, namun juga mau melakukan tugas-tugas ekstra seperti mau bekerja sama, tolong menolong, memberikan saran kepada sesama karyawan, berpartisipasi aktif, memberikan pelayanan ekstra dan mau menggunakan waktu kerja secara efisien dan efektif.

Budaya bekerja keras, kerja cerdas serta kerja ikhlas sebagai perwujudan OCB (Organizational Citizenship Behavior) untuk melakukan perbaikan diri, tidak malas, produktif dan mampu memanfaatkan ICT (Information and Communication Technology), serta kepedulian sejati oleh para karyawan akan kepentingan konsumen dan atau pelanggan, yang pada akhirnya mampu mendorong terciptanya kinerja karyawan sesuai harapan.

Berdasarkan uraian pada latar belakang tersebut terdapat beberapa research gap dari hasil pengamatan pada penelitian terdahulu seperti :

1. Sementara research lainnya yakni penelitian yang dilakukan oleh Yusran Assagaf (2012), untuk meningkatkan kinerja karyawan, lebih menekankan pada peningkatan inisiatif individu, toleransi resiko, dan dukungan manajemen dalam budaya kerja.

2. Penelitian yang dilakukan oleh Mariman Darto (2014), untuk meningkatkan kinerja karyawan lebih menekankan pada peran perilaku organizational citizenship behavior (OCB) dalam perspektif teoretis dan empiris, seperti ; kepemimpinan transformasional, religiusitas karyawan, kepuasan kerja, budaya organisasi, kepribadian dan tanggung jawab sosial karyawan.

3. Penelitian yang dilakukan oleh Johana Susanti Gunawan et.al. (2014), untuk meningkatkan kinerja lebih mendorong pada peran perilaku OCB dengan menggunakan metode SEM (Structural Equation Model) dan SmartPLS (Smart Partial Linear Regression).

4. Pengaruh Person Job Fit (Pj-Fit) dan Pendidikan Terhadap Kinerja Karyawan pada PT. Citra Putra Kebun Asri (CPKA) (Jaya, Sulaiman, \& Rusvitawati, 2019). Penelitian ini dilakukan untuk mengeksplorasi hubungan Person Job Fit (PJ-Fit), dan Pendidikan terhadap Kinerja Karyawan di PT. Citra Putra Kebun Asri (CPKA). Populasi penelitian ini adalah 477 karyawan PT. Citra Putra Kebun Asri (CPKA). Untuk menentukan sampel, penelitian ini menggunakan Slovin Formula. Kuesioner dibagikan kepada 83 responden sampel. Data dianalisis dengan menggunakan SPSS Software Versi 19.0 dan Regresi Linier. Hasil penelitian menunjukkan bahwa Person Job Fit (PJ-Fit) dan Pendidikan berpengaruh signifikan terhadap Kinerja Karyawan.

Sementara ketiga peneliti yang disebutkan terdahulu lebih menekankan pada penggunaan metode analisis regresi sederhana (Simple linear regression) dan regresi linear berganda (Multiple linear regression).

Tujuan yang hendak dicapai dari penelitian ini adalah :

1. Untuk mengkaji, menganalisis dan mengetahui bahwa Budaya Kerja berpengaruh signifikan terhadap Kinerja Karyawan PT Kaltrabu Indah Tour \& Travel Banjarmasin.

2. Untuk mengkaji, menganalisis dan mengetahui bahwa Organizaional Citizenship Behavior (OCB) berpengaruh signifikan terhadap Kinerja Karyawan PT Kaltrabu Indah Tour \& Travel Banjarmasin.

3. Untuk mengkaji, menganalisis dan mengetahui bahwa Budaya Kerja dan OCB secara simultan berpengaruh signifikan terhadap Kinerja Karyawan PT Kaltrabu Indah Tour \& Travel Banjarmasin 
https://ejurnal.stimi-bjm.ac.id/index.php/JRIMK

\section{METODE PENELITIAN}

Penelitian yang digunakan adalah penelitian eksplanetori yang bersifat asosiatif, merupakan penelitian yang bertujuan untuk mengetahui hubungan antara dua variabel atau lebih (Sugiyono, 2005:69). Dalam hal ini adalah penelitian yang bersifat menjelaskan pengaruh antar variabel seperti; variabel budaya kerja dan variabel organizational citizenship behavior (OCB) terhadap kinerja karyawan.

\section{Lokasi Penelitian}

Penelitian ini dengan mengambil obyek pada PT Kaltrabu Indah Tour \& Travel Banjarmasin.

\section{Populasi}

Menurut Sugiyono (2001:72) populasi adalah wilayah generalisasi yang terdiri atas obyek/subyek yang mempunyai kualitas dan karakteristik tertentu yang ditetapkan oleh peneliti untuk dipelajari dan kemudian ditarik kesimpulannya. Dalam penelitian ini yang menjadi populasinya adalah seluruh karyawan PT Kaltrabu Indah Tour \& Travel Banjarmasin yang berjumlah sebanyak 35 karyawan.

\section{Sampel}

Berdasarkan jumlah populasi di atas, jumlah karyawan sebanyak 35 orang ini dinyatakan sebagai populasi. Jadi jika populasi sudah diketahui, maka dasar penentuan jumlah sampel agar memberikan hasil yang akurat, penulis menggunakan sampel jenuh atau sampel total sebagai sensus, yakni keselurah anggota populasi dinyatakan sebagai sampel. Dengan demikian sampel responden dalam penellitian ini ditetap sebanyak 35 orang.

\section{HASIL PENELITIAN DAN PEMBAHASAN}

\section{Hasil Analisis Parsial Budaya Kerja Terhadap Kinerja}

Tabel 1 Budaya Kerja Terhadap Kinerja

\begin{tabular}{|c|c|c|c|c|c|}
\hline Model & $\mathrm{R}$ & R Square & Adjusted R Square & \multicolumn{2}{|c|}{$\begin{array}{l}\text { Std. Error of } \\
\text { the Estimate }\end{array}$} \\
\hline 1 & $941^{\mathrm{a}}$ & 886 & 882 & 498 & \\
\hline \multicolumn{6}{|c|}{ a. Predictors: (Constant), X1 } \\
\hline \multicolumn{6}{|c|}{ Coefficients $^{a}$} \\
\hline \multirow[t]{3}{*}{ Model } & \multicolumn{2}{|c|}{ Unstandardized } & Standardized & $\mathrm{t}$ & Sig. \\
\hline & \multicolumn{2}{|c|}{ Coefficients } & Coefficients & & \\
\hline & B & Std. Error & Beta & & \\
\hline (Con & 20.935 & 2.4 & & 8.603 & .000 \\
\hline \multicolumn{6}{|l|}{ stant) } \\
\hline $\mathrm{X} 1$ & .677 & .0 & .941 & 15.980 & .000 \\
\hline
\end{tabular}

a. Dependent Variable: Y

\section{Hasil Analisis Parsial Organizational Citizenship Behavior Terhadap Kinerja}

Tabel 2 Organizational Citizenship Behavior Terhadap Kineria

\begin{tabular}{|c|c|c|c|c|}
\hline Model & $\mathrm{R}$ & R Square & Adjusted R Square & $\begin{array}{l}\text { Std. Error of } \\
\text { the Estimate }\end{array}$ \\
\hline 1 &, $880^{\mathrm{a}}$ &, 775 &, 768 & 699 \\
\hline \multicolumn{5}{|c|}{ a. Predictors: (Constant), X2 } \\
\hline
\end{tabular}

\begin{tabular}{cccccc}
\multicolumn{7}{c}{ Coefficients $^{\mathbf{a}}$} \\
\hline Model & Unstandardized & Standardized & t & Sig. \\
\hline \multicolumn{7}{c}{ Coefficients } & Coefficients & & \\
\hline B & td. Error & Beta & & \\
\hline Constant) & 2.203 & 3.532 & & 6.285 & .000 \\
\hline X2 & 1.054 & .099 & .880 & 0.650 & .000 \\
\hline
\end{tabular}

Dependent Variable: Y

Hasil Analisis Simultan Budaya Kerja dan Organizational Citizenship Behavior Terhadap Kinerja

Tabel 3

Analisis Simultan Budaya Kerja dan Organizational Citizenship Behavior Terhadap Kinerja

Model Summary

\begin{tabular}{|c|c|c|c|c|}
\hline Model & $\mathrm{R}$ & $\begin{array}{c}\mathrm{R} \\
\text { Square }\end{array}$ & $\begin{array}{l}\text { Adjusted } \\
\text { R Square }\end{array}$ & $\begin{array}{c}\text { Std. Error } \\
\text { of the Estimate }\end{array}$ \\
\hline 1 & $.954^{\mathrm{a}}$ & .909 & .904 & .450 \\
\hline
\end{tabular}

\begin{tabular}{cccccc}
\multicolumn{8}{c}{ ANOVA $^{\mathbf{a}}$} \\
\hline Model & $\begin{array}{c}\text { Sum of } \\
\text { Squares }\end{array}$ & df & $\begin{array}{c}\text { Mean } \\
\text { Square }\end{array}$ & F & Sig. \\
\hline Regression & 65.106 & 2 & 32.553 & 160.417 & $.000^{\mathrm{b}}$ \\
\hline Residual & 6.494 & 32 & .203 & & \\
\hline Total & 71.600 & 34 & & & \\
\hline
\end{tabular}

a. Dependent Variable: $\mathrm{Y} \backslash$

b. Predictors: (Constant), X1, X2

\section{Hasil Hipotesis}

Tabel 4 Hipotesis

\begin{tabular}{clcccc} 
No & \multicolumn{1}{c}{ Hipotesis } & $\mathbf{r}^{\mathbf{2}}$ & thitung & tabel & Keterangan \\
\hline 1 & Budaya Kerja $\Rightarrow$ Kinerja & 0,886 & 15,980 & 1,689 & Signifikan \\
\hline 2 & $\begin{array}{l}\text { Organizatonal Citizenship } \\
\text { Behaviour } \Rightarrow \text { Kinerja }\end{array}$ & 0,775 & 10,650 & 1,689 & Signifikan \\
\hline 3 & $\begin{array}{l}\text { Budaya Kerja } \\
\text { dan Organizatonali Citizenship } \\
\text { Behaviour } \Rightarrow \text { Kinerja }\end{array}$ & 0,909 & Fhitung & Ftabel & Signifikan \\
& & 160,41 & 2,87 & \\
\hline
\end{tabular}

Berdasarkan Tabel 4 di atas dapat dijelaskan hasil pengujian hipotesis sebagai berikut :

1. Hipotesis ke satu (H1) diterima, yang artinya bahwa Budaya Kerja berpengaruh secara signifikan terhadap Kinerja Karyawan, 
sebesar $88,6 \%$ dan sisanya $11,4 \%$ Kinerja karyawan dipengaruhi oleh faktor lain.

2. Hipotesis ke dua $(\mathrm{H} 2)$ diterima, yang artinya bahwa Organizational Citizenship Behaviour berpengaruh secara signifikan terhadap Kinerja Karyawan, sebesar $77,5 \%$ dan sisanya 12,5\% Kinerja Karyawan dipengaruhi oleh faktor lain.

3. Hipotesis Ke empat (H3) diterima yang artinya bahwa Budaya Kerja dan Organizational Citizenship Behaviour secara simultan berpengaruh secara signifikan terhadap Kinerja Karyawan, sebesar $90,9 \%$ dan sisanya $9,1 \%$ Kinerja Karyawan dipengaruhi oleh faktor lain.

\section{PENUTUP}

Secara parsial pengaruh Budaya Kerja terhadap Kinerja Karyawan PT. Kaltrabu Indah Tour \& Travel Banjarmasin berdasarkan perhitungan korelasi ( $\mathrm{r}$ ) sebesar 0,941, maka dapat dinyatakan bahwa hubungan antara Budaya Kerja dan Kinerja Karyawan adalah positif, artinya semakin baik Budaya Kerja maka akan semakin meningkatkan Kinerja karyawan, sedangkan berdasarkan perhitungan koefesien diterminasi (r2) bahwa Budaya Kerja berpengaruh terhadap kinerja karyawan sebesar $88,6 \%$ sedangkan $11,4 \%$ sisanya dipengaruhi oleh faktor lain.

Secara parsial pengaruh Organization Citizenship Behaviour terhadap Kinerja Karyawan PT. Kaltrabu Indah Tour \& Travel Banjarmasin berdasarkan perhitungan korelasi (r) sebesar 0,880, maka dapat dinyatakan bahwa hubungan antara Organization Citizenship Behaviour dan Kinerja Karyawan adalah positif, artinya semakin baik Organization Citizenship Behaviour maka akan semakin meningkatkan Kinerja karyawan, sedangkan berdasarkan perhitungan koefesien diterminasi (r2) bahwa Organization Citizenship Behaviour berpengaruh terhadap kinerja karyawan sebesar $77,5 \%$ sedangkan $23,5 \%$ sisanya dipengaruhi oleh faktor lain.

Secara silmultan Budaya Kerja dan Organization Citizenship Behaviour terhadap Kinerja Karyawan PT. Kaltrabu Indah Tour \& Travel Banjarmasin.

\section{Saran}

Saran untuk PT. Kaltrabu Indah Tour \& Travel Banjarmasin.

1. PT. Kaltrabu Indah Tour \& Travel Banjarmasin harus meningkatkan lagi Budaya Kerja para karyawannya, dengan Budaya Kerja sesuai dengan visi misi membuat perusahaan menjadi profesional dalam bekerja dan menciptakan kerja sama antar pegawai menjadi kreatif, jujur, tekun, berintegritas, rasional dan bertangungjawab.
2. PT. Kaltrabu Indah Tour \& Travel Banjarmasin harus meningkatkan lagi Organization Citizenship Behaviour (OCB), dengan Organization Citizenship Behaviour yang baik maka akan membuat perusahaan semakin harmonis dengan hubungan antar karyawan sehingga tercipta peningkatan kinerja

Saran pada Peneliti Selanjutnya

Bagi para peneliti selanjutnya yang akan melakukan penelitian sejenis diharapkan mengambil indikator variable lainnya dan dalam tahapan selanjutnya dalam pengumpulan data disamping menggunakan dengan cara menyebar kuesioner atau angket, juga bisa bisa langsung berinteraksi dengan karyawan melalui interview secara langsung guna dapat mempertajam

dalam mendiskripsikan hasil analisis dan pembahasan.

\section{DAFTAR PUSTAKA}

Aldri Frinaldi, 2014, Pengaruh Budaya Kerja Pegawai Negeri Sipil Terhadap Pelayanan Publik Dinas Catatan Sipil dan Kependudukan Kota Payakumbuh, Humanus, Vol. XIII No.2 Tahun 2014, FIS Universitas Negeri Padang

Anoraga, Pandji. (2009). Psikologi Kerja. Jakarta: Rineka Cipta.

Arikunto, Suharsimi, (2003), Prosedur Penelitian Suatu Pendekatan Praktek, Edisi Revisi V, Rineka Cipta, Jakarta.

Bernardin, H.John, dan Joyce E.A.Russel. 1993. Human Resource Management : An Experential Approach. Singapore: Mc. Graw Hill, Inc.

Bohlander, George., and Snell, Scott. (2010). Principles of Human Resource. Management, 15th ed. Mason, OH: South Western - Cengage Learning

Chahal, H., \& Mehta, S. (2010). Antecedents and consequences of organizational citizenship behavior (OCB): A conceptual framework in reference to health caresector. Journal of Occupational and Organizational Psychology, 75, 339-356.

Chen, Li Yueh, 2009, Examining The Effect Of Organization Culture And Leadership Behaviors On Organizational Commitment, Job Satisfaction, Adan Job Performance At Small And Middle-Sized Firm of

Taiwan, Journal of 


\begin{tabular}{|c|c|c|}
\hline & $\begin{array}{cr}\text { American } & \text { Academy } \\
\text { Business, Sep 2004, 5, 1/2, 432-438. }\end{array}$ & $\begin{array}{l}\text { on Local Water Companies in South } \\
\text { Kalimantan Province". International }\end{array}$ \\
\hline Darto & $\begin{array}{l}\text { Mariman, 2014, Peran Organizational } \\
\text { Citizenship } \\
\text { Peningkatan }\end{array}$ & $\begin{array}{l}\text { Journal of Business and Management } \\
\text { Invention (IJBMI) Vol. } 6 \text { Issue } 11 \\
\text { Version 1. }\end{array}$ \\
\hline
\end{tabular}

Publik : Sebuah Analisis Teoretis Dan

Empiris, Jurnal Borneo Administrator/

Volume 10/ No. 1/2014, PKP2A III Lembaga

Administrasi Negara, Samarinda

Dessler Gary, (2006), Human Resource Management (Manajemen Sumber Daya Manusia), Edisi ke 9 Jilid 2, Edisi Bahasa Indonesia, Indeks, Jakarta.

Faris Ihsan. 2014. Reformasi Budaya Kerja Pada Birokrasi Pemerintah. Artikel pada Website BKD dan Diklat Provinsi NTB. Http://Bkddiklat.Ntbprov.Go.Id/WpContent/ Uploads/2014/09/Reformasi-Budaya-KerjaPada-Birokrasi-Pemerintah.Pdf

Fathoni. 2006. Manajemen Sumber Daya Manusia. Penerbit PT. Rineka Cipta, Jakarta.

Ghozali, Imam, (2011). Aplikasi Analisis Multivariate dengan Program SPSS, Semarang, UNDIP.

Gomes, Faustino,Cardoso, 2001. Manajemen Sumber Daya Manusia, Andi Offset, Yogyakarta.

Gunawan Susanti Johana, Pinkan Datun Solang, Endo Wijaya Kartika, 2014,

Organizational Citizenship Behavior Yang Berpengaruh Pada Kinerja Karyawan Dan Kepuasan Konsumen Di Hotel Sheraton Surabaya, Universitas Kristen Petra, Surabaya.

Hartanto. 2000. Analisis Produktivitas kerja kajian implikasi budaya perusahaan (Kasus PT. Bank BNI Cabang UNDIP), Thesis Program Studi Magister Managemen. Universitas Diponegoro.

Hasibuan, Malayu S.P., (2005), Manajemen Sumber Daya Manusia, CV. Haji Mas Agung, Jakarta.

Hasibuan, Malayu S.P., (2012), Manajemen Sumber Daya Manusia, Edisi Revisi, Bumi Aksara, Jakarta

Zhang, D. (2011). Organisational Citizenship Behavior. White Pape

Henry Simamora, (2004), Manajemen Sumber Daya Manusia, Edisi III, STIE YKPN, Yogyakarta.

Jahangir, Nadim, Akbar M.M, Haq, Mahmudul. 2004. Organizational Citizenship Behavior : Its Nature and Antecedents. BRAC University Journal, Vol. 1, No. 2, 75-85

Jaya Prima Fanlia, et.al. "Organizational Citizenship Behaviour As Intervening variables of the influence of Person Job Fit and Person Organization Fit on Employee Peformance
Jaya, F. P., Sulaiman, S., \& Rusvitawati, D. (2019). Pengaruh Person Job Fit (Pj-Fit) dan Pendidikan Terhadap Kinerja Karyawan pada PT. Citra Puta Kebun Asri (CPKA). Jurnal Riset Inspirasi Manajemen Dan Kewirausahaan, 3(1), 12-21. https://doi.org/10.35130/jrimk.v3i1.42

Kementerian PAN \& RB Republik Indonesia, (2012), Nomor 39 Tahun 2012, Tentang Pengembangan Budaya Kerja, Jakarta.

Kementerian PAN-RI,(2002), Pedoman Pengembangan Budaya Kerja Aparatur Negara, Jakarta.

Mangkunegara, AP., (2006), Evaluasi Kinerja Sumber Daya Manusia, Cetakan ke 10, PT. Refika Aditama, Bandung.

Mangkuprawira, Sjafri. 2003. Manajemen Sumber Daya Manusia Strategik. Jakarta: Ghalia Indonesia .

Mathis, R.L., \& J.H. Jackson, (2012), Manajemen Sumber Daya Manusia, PT. Salemba Empat, Jakarta.

Mathis, Robert L. dan John H. Jackson, 2001, Human Resource Management, Terj. "Jimmy Sadeli dan Bayu Prawira Hie, Manajemen Sumber Daya Manusia, Jakarta: Salemba Empat, 2001

Maulana, Gian G., dan Rispianda, 2015, Sistem Informasi Pelayanan Jasa Tour \& Travel Berbasis Website Electronic Commerce (Studi Kasus Ninetours Indonesia), Reka Integra ISSN: 23385081 CJurusan Teknik Industri Itenas | No.01 | Vol.03 Jurnal Online Institut Teknologi Nasional(ITENAS), Bandung, Januari 2015 Reka Integra- 49

Ndraha, Taliziduhu, (2003), Budaya Organisasi, Cetakan kedua, PT. Rineka Cipta, Jakarta.

Nirman, Umar, 2004. Perilaku Organisasi, Cetaka ketiga, Penerbit CV. Citra Media, Surabaya.

Nitisemito, Alex S., 2002. Manajemen Personalia, Ghalia Indonesia : Jakarta

Noe, Hollenbeck, Gerhart, Wright, 2008, Human Resources Management, International Edition. Newyork : The McGraw-hill, Companies, Inc.

Organ, Dennis, W., (1997), A Reappraisal And Reinterpretation of The Satisfaction 
Causes Performance Hypothesis. Academy of Management, Review, 2.

Osborn dan Plastrik.2002. Manajemen Sumber Daya Manusia. Yogyakarta. BPFE

Peraturan Menteri PAN dan RB Nomor 10 Tahun 2011 tentang Pedoman Pelaksanaan Program Manajemen Perubahan.

Podsakoff, Philip M., MacKenzie, S.B., Paine, J.B., dan Bachrach, D.G. (2009). Organizational Citizenship Behavior: a Critical Review of Theoretical Empirical Literature and Suggestions for Future Research. Journal of Management, 26 (3): 513-563

PramestiIntan Annur, 2015, Pengaruh Person Organization Fit Terhadap Motivasi harapan berkembang dan Kinerja Pada Karyawan PT Bank Pembangunan Daerah Jawa Timur (Bank Jatim) Cabang Lamongan, Jurusan Pendidikan Ekonomi, Fakultas Ekonomi, Universitas Negeri Surabaya, Surabaya

Robbins, Stephen P., (2007), Perilaku Organisasi, Buku I, Edisi 12, Salemba Empat, Jakarta.

Ruky, A. 2006. Sumber Daya Manusia Berkualitas Mengubah Visi Menjadi Realitas. Cetakan Kedua. Jakarta: PT. Gramedia Pustaka Utama.

Sekaran, Uma. (2006). Metode Penelitian Untuk Bisnis. Buku 1 dan 2. Penerbit Salemba Empat. Jakarta. Simamora, Henry, 2004, Manajemen Sumber Daya Manusia, Edisi Ketiga, Cetakan\

Pertama, Bagian Penerbitan STIE YKPN, Yogyakarta.

Soedjono. 2005. Pengaruh Budaya Organisasi terhadap Kinerja Organisasi dan kepuasan Kerja Karyawan pada Terminal Penumpang Umum di Surabaya. Jurnal Manajemen dan kwirausahaan Vol. 7 No. 1. STIESIA Surabaya.

Sugiyono. 2012. Metode Penelitian Kuantitatif Kualitatif dan R\&D. Bandung: Alfabeta.

Sugiyono, 2013, Statistik Untuk Penelitian, Alfabeta, Bandung.

Supriyadi, Gering \& Triguno, (2006), Budaya Kerja Organisasi Pemerintah, Lembaga Administrasi Negara RI, Jakarta.

Titisari, Purnamie. 2014.Peran Organizatonal Citizenship Behavior (OCB). Jember: Mitra Wacana Media

Triguno,(2004), Budaya Kerja : Menciptakan Lingkungan Kerja Yang Kondusif Untuk Meningkatkan Produktivitas

Kerja, Edisi 6, Golden Trayon, Jakarta.

Wirawan. 2009. Evaluasi Kinerja Sumber Daya Manusia : Teori, Aplikasi dan Penelitian. Jakarta : Salemba

Empat
Yusran Assagaf, 2012, Pengaruh Budaya Kerja Terhadap Kinerja Karyawan Pada PT Hadji Kalla Cabang Alauddin Makassar,URL:http://repository.unhas.ac. $\mathrm{id} /$ handle/123456789/1657,Uni versitas Hasanuddin, Makassar,

Yuswita Effy, et.al., 2012, Pengaruh Budaya Kerja Terhadap Kinerja Karyawan Di Koperasi Karyawan Redrying Bojonegoro, Fakultas Pertanian, Universitas Brawijaya, Malang.

\section{Profil Penulis}

1. Fanlia Adiprimadana Sanjaya, S.E., M.M., Fakultas Ekonomi, Program Studi Manajemen, Universitas Islam Kalimantan Muhammad

Arsyad Al-Banjari (UNISKA MAB) Banjarmasin, J1. Adhyaksa No.2 Kayutangi 70123

Email : fanliadana@gmail.com 